\title{
GÊNEROS TEXTUAIS E SEQUÊNCIA DIDÁTICA: FERRAMENTAS PARA O DESENVOLVIMENTO DAS PRÁTICAS SOCIAIS DE LEITURA E DE ESCRITA NUMA PERSPECTIVA SOCIODISCURSIVA
}

\section{TEXTUAL GENRES AND DIDACTIC SEQUENCE: TOOLS FOR THE DEVELOPMENT OF SOCIAL READING AND WRITING PRACTICES IN A SOCIODISCURSIVE PERSPECTIVE}

\author{
Suely de Sousa Martins ${ }^{1}$ \\ Universidade Regional do Cariri \\ Luiz Henrique de Oliveira ${ }^{2}$ \\ Universidade Regional do Cariri \\ Raimundo Nonato da Silva Salviano ${ }^{3}$ \\ Universidade Regional do Cariri \\ José Marcos Ernesto Santana de França ${ }^{4}$ \\ Universidade Regional do Cariri
}

\begin{abstract}
RESUMO
O ensino de Língua Portuguesa ainda é problemático, principalmente, no que diz respeito em desenvolver no alunado as habilidades de leitura e de escrita de forma proficiente, como pretendem os documentos oficiais PCN e BNCC. Em vista disso, defendemos que os gêneros textuais, quando mediados por práticas pedagógicas significativas, podem atuar no desenvolvimento das capacidades de linguagem, bem como podem despertar o interesse do aluno para a aprendizagem e desenvolvimento das habilidades de leitura e de escrita, evidenciando que essas atividades educativas não estão apenas dentro da sala de aula, mas que se configuram como instrumentos para o exercício de cidadania no mundo real e no convívio social. Sendo assim, este trabalho tem como objetivo discutir e apresentar os gêneros textuais e a sequência didática como ferramentas para o desenvolvimento da leitura e da escrita como práticas sociais e discursivas de linguagem para o exercício sociopolítico de cidadania. E para ilustrar como isso é possível, propomos uma aplicação didático-pedagógica, ou seja, um uso prático com o gênero textual notícia, explorando o processo de retextualização de um poema em uma notícia. Essa perspectiva de abordagem de ensino de língua segue a orientação teórico-metodológica do Interacionismo Sociodiscursivo (ISD), a partir de autores como Bronckart (1999), Schneuwly eDolz(2004).
\end{abstract}

PALAVRAS-CHAVE: Gêneros Textuais; Escrita; Leitura; ISD.

\begin{abstract}
Portuguese language teaching is still problematic, mainly, with regard to developing student skills in reading and writing proficiently, as the official documents PCN and BNCC intend. In view of this, we argue that textual genres, when mediated by significant pedagogical practices, can act in the development of language skills, as well as can arouse the student's interest in learning and developing reading and writing skills, showing that these educational objects are not only inside the classroom, but are configured as instruments for the exercise of citizenship in the real world

\footnotetext{
${ }^{1}$ Graduanda do curso de Letras-Língua Portuguesa. E-mail: suellymartins01@gmail.com

${ }^{2}$ Graduando do curso de Letras-Língua Portuguesa. E-mail:luizoliveira9802@gmail.com

${ }^{3}$ Graduando do curso de Letras-Língua Portuguesa. E-mail:rn6498850@gmail.com

${ }^{4}$ Doutor em Linguística e pós-doutor na área de Linguística Aplicada. Professor do Departamento de Línguas e
} Literaturas e do Programa de Pós-Graduação em Letras. E-mail: marcos.franca@urca.br
\end{abstract}


and in social life. Therefore, this work aims to discuss and present textual genres and the didactic sequence as tools for the development of reading and writing as social practices and discursive language for the socio-political exercise of citizenship. And to illustrate how this is possible, we propose a didactic-pedagogical application, that is, a practical use with the news textual genre, exploring the process of retextualizing a poem in a news story. This perspective of language teaching approach follows the theoretical-methodological orientation of Sociodiscursive Interactionism (ISD), from authors such as Bronckart (1999), Schneuwly and Dolz (2004).

KEYWORDS: Textual Genres; Writing; Reading; ISD.

\section{INTRODUÇÃO}

As noções de gêneros textuais e de sequência didática propostas pelo Interacionismo Sociodiscursivo (ISD) se mostram relevantes para o ensino de Língua Portuguesa no momento atual. Ao longo dos anos, as ciências da linguagem têm explorado amplamente a natureza dos gêneros textuais e os métodos pelos quais possam ser abordados produtivamente, a fim de aprimorar as práticas de leitura e de escrita. Nas diversas teorias voltadas para este estudo, os gêneros textuais são analisados sob diferentes concepções. Boa parte delas, porém, tem em comum a percepção da necessidade de ensiná-los levando em consideração seus aspectos socioculturais, pois são estes que possibilitam um ensino que desperta o interesse dos discentes pela aprendizagem da língua materna e favorecem, assim, as práticas sociais de leitura e de escrita.

Diante disso, amparando-nos, sobretudo, na proposta teórico-metodológica do Grupo de Genebra, pretendemos evidenciar que os gêneros textuais, quando apresentados como ferramentas de interação social pelos professores, são capazes de tornar as aulas de língua materna mais efetivas e, por conseguinte, melhorar o desempenho dos alunos no emprego da leitura e da escrita nos diversos contextos comunicativos, tornando-os usuários proficientes da língua. A sequência didática, nesse sentido, como método pedagógico, pode possibilitar o ensino de gêneros textuais nessa perspectiva social e discursiva, atuando como instrumento mediador entre as práticas de ensino e o cotidiano dos alunos.

O texto está dividido em quatro seções. $\mathrm{Na}$ seção um, buscamos apresentar a proposta teórico-metodológica da perspectiva interacionista sociodiscursiva e suas contribuições para o ensino de práticas sociais de linguagem por meio de gêneros textuais. $\mathrm{Na}$ seção dois, expomos e discutimos a definição do que é uma sequência didática como proposta pedagógica para o ensino de gêneros textuais na escola. Na seção três, por sua vez, mostramos a presença e a influência de tais perspectivas nos Parâmetros Curriculares Nacionais (PCN, 1998) e na Base Nacional Comum Curricular (BNCC, 2018), documentos oficiais que regulamentam o sistema de ensino brasileiro. Já na seção quatro, propomos a construção de uma sequência didática a partir do gênero notícia jornalística e a sua aplicação pedagógica. Por fim, nossas considerações finais.

\section{A perspectiva do Interacionismo Sociodiscursivo(ISD): contribuições para o ensino}

O Grupo de Genebra, formado, principalmente, por Jean-Paul Bronckart, Joaquim Dolz e Bernard Schneuwly, diligentes pesquisadores da Universidade de Genebra sobre a Didática das línguas e o seu ensino, desenvolveu a Teoria dos Gêneros Textuais vinculados à educação como parte da proposta teórico-metodológica a que eles denominaram de Interacionismo Sociodiscursivo (ISD). Tais pesquisadores apresentam os gêneros textuais a partir de uma visão social e discursiva, enfatizando-os como ferramentas linguístico-discursivas de ação linguageira que favorecem a interação entre os sujeitos.

Esse grupo foi além da cognição individual, explorada por estudos anteriores, partindo para um conceito mais amplo, a interação social, tomando como elemento principal para as suas 
investigações os aspectos do contexto em que as ações de linguagem se materializam. Por isso, uma das maiores contribuições do ISD para o ensino foi a reflexão sobre a necessidade de contextualização das atividades de leitura e escrita, sugerindo a criação de condições para que tais atividades sejam executadas conscientemente pelos discentes.

Bronckart(1999) descreve o caminho trilhado na realização da linguagem através da produção textual, de maneira que podemos compreender como o gênero textual atua no ensino de leitura e de escrita. Inicialmente, o autor divide as ações de linguagem em dois níveis: o sociológico e o psicológico. O nível sociológico é responsável pela organização do trabalho representativo dentro do texto. Nele encontramos os parâmetros contextuais da atividade da linguagem que se referem à interação social em curso, ao ato material de enunciação e ao conteúdo referencial disponível na memória dos agentes. Estes parâmetros são a base que orientam a produção textual, desde a escolha do gênero a toda a arquitetura do texto. Depois da construção dessa base, seguimos para o nível psicológico, no qual encontramos as operações de textualização. Dentro desse nível, estão compreendidas as operações de ancoragem textual, de adequação a um modelo de linguagem e de constituição de estratégias linguísticas e discursivas. Por fim, chegamos ao produto final, isto é, a materialização da linguagem, o texto (CRISTOVÃO; NASCIMENTO, 2011).

Partindo dessas considerações, podemos observar que, ao longo de uma produção textual, o discente trabalha leitura, escrita e atividades voltadas à interação social. Isso evidencia a importância do ensino de língua materna a partir de uma abordagem contextualizada. Como nos mostra Bronckart (1999), na realização do texto, o discente utiliza-se tanto das capacidades sociais, como das psíquicas. Por esse motivo, as instituições de ensino devem trabalhar os gêneros textuais, buscando, simultaneamente, o desenvolvimento de tais capacidades por meio de atividades linguageiras significativas. Os pesquisadores Schneuwly e Dolz (2004) afirmam que os gêneros textuais podem ser considerados "[...] formas relativamente estáveis tomadas pelos enunciados em situações habituais, entidades culturais intermediárias que permitem estabilizar os elementos formais e rituais das práticas de linguagem" (p. 74).De acordo com esta afirmação, ainda que as práticas comunicativas sejam heterogêneas, os gêneros textuais mantêm certa regularidade em sua estrutura, que pode ser analisada, basicamente, em três aspectos:

[...] 1) os conteúdos e os conhecimentos que se tornam dizíveis por meio dele; 2) os elementos das estruturas comunicativas e semióticas partilhadas pelos textos reconhecidos como pertencentes ao gênero; 3) as configurações específicas de unidades de linguagem, traços, principalmente, da posição enunciativa do enunciador e dos conjuntos particulares de seqüências textuais e de tipos discursivos que formam sua estrutura. (SCHNEUWLY; DOLZ, 2004, p. 75)

Para os autores, "[...] é através dos gêneros que as práticas de linguagem materializam-se nas atividades dos aprendizes"'(SCHNEUWLY; DOLZ, 2004, p. 74 [grifo no original]).Assim, os gêneros devem ser abordados didaticamente como ponte para a realização da linguagem, atendendo as diversas finalidades dos indivíduos em situações comunicativas de interação social. Se o ensino de leitura e de escrita em sala de aula parte de uma abordagem contextualizada, é provável que desperte o interesse dos alunos, pois verão que os gêneros textuais podem ser realmente úteis em sua vida, atuando como mediadores para a efetivação de diversas atividades sociais que requerem usos de linguagens.

Nesse sentido, os gêneros textuais passam a ser inseparáveis do ensino de leitura e de escrita e é por esse motivo que todas as atividades de letramento, em sala de aula, devem ser executadas por intermédio deles. Na verdade, mesmo que a escola não os apresente como objeto de estudo nas práticas de leitura e de escrita, qualquer texto, lido ou produzido, enquadra-se em algum gênero textual. Por isso, Schneuwly e Dolz (2004) fazem uma crítica ao modo como escolas empregam os gêneros textuais em sua metodologia de ensino, cujo foco é, meramente, 
apresentar os gêneros dentro do contexto escolar, sem recorrer à variada gama destes em outros contextos nos quais os alunos estão inseridos. Acreditamos, pois, que o problema esteja no fato de as escolas não assimilarem, nas práticas pedagógicas, os gêneros textuais com os quais os discentes têmmais contatos. Porisso, uma possível "sistematização" dos gêneros a serem trabalhados e as práticas de escrita e leitura de textos (o material em si), concernentes a esses gêneros, são necessárias.

Assim, em vez de propor um trabalho, por exemplo, com a notícia, na tentativa de preencher as partes de um gênero textual e analisar com os alunos apenas os aspectos estruturais, o ideal seria que o professor tomasse exemplos de notícias a respeito de algo que realmente aconteceu no entorno da vida social dos alunos, pelo menos em princípio, trazendo para a sala de aula uma situação comunicativa real. Sendo assim, o trabalho didático com os gêneros textuais abordados com um caráter de ferramenta de ação de linguagem utilizável na sociedade pode despertar nos alunos um maior interesse por estudá-los e, assim, levá-los a adquirir as habilidades de leitura e de escrita desejáveis.

O professor pode trabalhar o texto de início, desde que as características do gênero sejam acompanhadas da leitura do texto. Sem o conhecimento das características do gênero em que o texto é vazado, o ensino de língua torna-se não tão significativo. Daí a importância de o aluno conhecer o gênero em si. A escola, por sua vez, seguindo a principal premissa do letramento social, deve sempre expandir os conhecimentos que os alunos recebem para a sua vida em sociedade. Na proposta apresentada pelo ISD, pois, são as construções reais de interação social que precisam ser centralizadas, porque são essas construções que permitem ao aluno conhecer a dinamicidade da língua e sua função sociocomunicativa.

Com a finalidade de levar a escola ao cumprimento de seu papel no ensino de leitura e de escrita a partir dos gêneros textuais, o Grupo de Genebra desenvolveu uma proposta teóricometodológica, a nosso ver, pedagogicamente viável e exequível, denominada sequência didática, que abordamos na próxima seção.

\section{Sequência didática e gêneros textuais como ferramentas pedagógicas para o ensino}

Diante do que foi discutido na seção anterior, podemos afirmar que as práticas sociais de linguagem proporcionam a interação entre o sujeito e o mundo por meio dos gêneros textuais, se tornando estes, pois, ferramentas eficientes para o ensino de leitura e de escrita e favorecendo o desenvolvimento e domínio efetivo das habilidades linguístico-discursivas dos discentes.

As manifestações linguageiras ocorrem através de textos, e estes se apresentam por meio de um determinado gênero textual. Isso demonstra que os gêneros são ferramentas indispensáveis para a sobrevivência do falante na sociedade. O sujeito, portanto, precisa apropriar-se deles para que possa atuar nas diferentes áreas sociocomunicativas da atividade humana. Segundo Bakhtin (2016), o domínio dos gêneros nos leva a um uso livre, no qual percebemos nossa individualidade e, assim, realizamos de forma acabada nosso discurso, refletindo, ainda, de maneira mais fluida e sutil a comunicação.

Vale ressaltar que o domínio de um gênero está além de apreender estruturas formais que estão fincadas em um ensino tradicional descontextualizado. Para que o aluno possa dominar os gêneros e utilizá-los adequadamente nas diversas atividades comunicativas, ele precisa conhecer a funcionalidade desse objeto de ensino, suas características linguísticas e sociais, para que possa observar os aspectos discursivos e, assim, compreender e produzir seus textos com autonomia e criticidade. Para isso, as instituições de ensino precisam se distanciar de práticas isoladas que promovem

[um] ensino tradicional da linguagem humana fundamentado na gramática, coesão e nas modalidades retóricas, bem como nos aspectos da coerência textual, [que] tem se mostrado altamente ineficiente, não se preocupando e não dando conta das situações 
específicas em que os indivíduos efetivamente utilizam a linguagem como instrumento de interação, reprodução e/ou alteração social. (MEURER, 2000 apud FRANCA, 2012, p. 151-152)

Os métodos tradicionais de ensino distanciam os discentes das verdadeiras e efetivas práticas linguageiras. Como demonstra o autor, essa educação fundamentada na gramática e nas modalidades retóricas não dá conta da complexidade que é o uso da linguagem e, por conseguinte, distancia os educandos das diversas capacidades envolvidas no ensino de língua, que vão além dessa visão formal. Uma consequência visível decorrente disso é a falta de familiaridade dos discentes com as práticas de linguagem em gêneros mais elaborados, por exemplo.

Os gêneros textuais, por sua vez, proporcionam um ensino de leitura e de escrita de maneira contextualizada. Todavia, quando tomados como objetos isolados e por si próprios, não são suficientes para um ensino que atue no desenvolvimento das capacidades da linguagem. Logo, os gêneros precisam ser mediados através de métodos pedagógicos que deem sentido às práticas educativas e apresentem um significado para o cotidiano do educando. Conforme Bronckart (2001 apud MARCUSCHI, 2008, p. 221), "O trabalho com gêneros é interessante na medida em que eles são instrumentos de adaptação e participação na vida social e comunicativa." Isso porque os discentes precisam observar na leitura, na escrita e nos usos de gêneros textuais, práticas sociais e discursivas de linguagem para que, assim, sintam-se atraídos e percebam que esses elementos não estão apenas dentro da sala de aula, mas que se apresentam, pois, como ferramentas para o exercício da cidadania.

Dolz, Noverraz e Schneuwly (2004) apresentam a sequência didática (doravante SD) como metodologia que media as práticas educativas e o ensino de gêneros textuais, através da construção de situações concretas de comunicação. Segundo os autores, uma SD será um conjunto de atividades sistematizadas acerca de um gênero textual, tendo como objetivo levar o aluno ao domínio do gênero trabalhado para que possa utilizá-lo de maneira mais adequada em uma determinada situação de comunicação (DOLZ; NOVERRAZ; SCHNEUWLY, 2004). Nas palavras de Marcuschi (2008, p. 214), "A finalidade de trabalhar com sequências didáticas é proporcionar ao aluno um procedimento de realizar todas as tarefas e etapas para a produção de um gênero". Sendo assim, uma SD busca trilhar um caminho para que o discente possa desenvolver as habilidades necessárias para a construção e adequação de um gênero textual nas diversas atividades linguageiras.

Essa proposta de ensino visa ao desenvolvimento das capacidades do educando para o domínio de um gênero textual, trabalhando aspectos discursivos, textuais e possibilitando, ainda, uma abordagem a partir de seu contexto social. Como afirmam Schneuwly e Dolz(2004), toda ação de linguagem leva o sujeito à utilização de inúmeras capacidades, desde a adaptação a um determinado contexto e referente, mobilização de diversas estruturas discursivas, assim como o domínio das operações psicolinguísticas e das unidades linguísticas.

A construção de uma SD permite ao professor a condução de seu trabalho para o desenvolvimento dessas capacidades. Aplicando atividades de aprendizagem e de avaliação, o docente poderá observar as reais dificuldades dos estudantes e, assim, trabalhá-las para o domínio de um gênero. Igualmente, essa transposição didática do conceito de gênero textual propicia a interação entre discente e professor, permitindo a criação de um diálogo, no qual essas duas personagens juntas compartilham aprendizados. Consequentemente, há uma maior possibilidade de o aluno, portanto, perceber dentro do ambiente escolar uma ação comunicativa real.

Opondo-se a metodologias de ensino que têm como ponto de vista o trabalho a partir de exercícios mecanicistas, uma SD tem por intuito promover atividades significativas que desenvolvam a consciência e a reflexividade acerca dos usos da linguagem. Essa proposta de didatização favorece, ainda, a abordagem de gêneros textuais mediante uma perspectiva de letramento que visa ao uso social da leitura e da escrita e não apenas à codificação e 
decodificação. Dolz, Noverraz e Schneuwly (2004), em vista disso, propõem um modelo de SD por meio de quatro etapas: apresentação da situação, produção inicial, módulos e produção final.

Buscaremos, aqui, brevemente, discutir cada estágio que compõe uma SD, seguindo o esquema da figura 1.
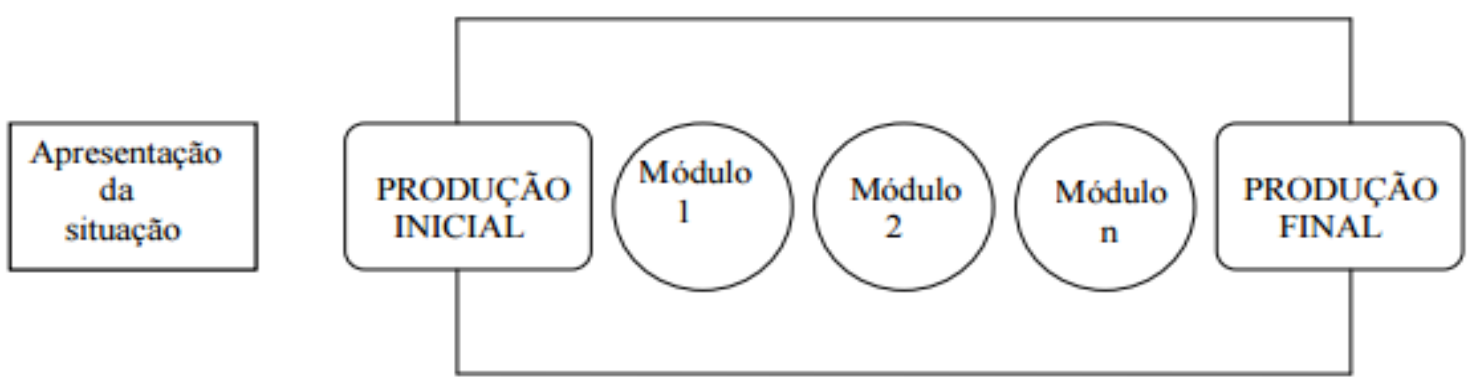

Figura 1: Esquema da sequência didática.

Fonte: Dolz, Noverraz e Schneuwly (2004, p. 98).

A apresentação da situação pauta-se na exposição do gênero a ser trabalhado, partindo da construção de um contexto de produção, no qual será apresentado o destinatário, o conteúdo temático, se a produção será a partir de um texto oral ou escrito e de que forma se dará a sua circulação. Esta etapa consiste na elaboração de um evento comunicativo significativo para que faça sentido na vida do discente. Ademais, o trabalho com diferentes exemplos do gênero proposto pode ser utilizado como ferramenta para evidenciar os aspectos sociodiscursivos e estruturais que o compõem. Em resumo, "A fase inicial de apresentação da situação, permite, portanto, fornecer aos alunos todas as informações necessárias para que conheçam o projeto comunicativo visado e a aprendizagem de linguagem que está relacionado" (DOLZ; NOVERRAZ; SCHNEUWLY, 2004, p. 100).

A primeira produção é o momento em que o aluno, por meio dos conhecimentos já adquiridos, produzirá um texto a partir do gênero que lhe foi proposto. Essa produção pode se dar de forma mais simplificada, tendo em vista que o maior objetivo é chegar à produção final que ocorrerá de forma mais complexa. É por meio desta primera produção que o professor poderá avaliar as dificuldades apresentadas pelo aluno e, assim, trabalhá-las no decorrer da SD. Logo, essa etapa guiará o trabalho do professor no planejamento das atividades para a apreensão de novas habilidades e o desenvolvimento das capacidades já trazidas. Cabe salientar que a SD possui um caráter dinâmico que busca adaptar suas atividades às necessidades apresentadas pelos alunos.

Mediante a análise dos textos que foram produzidos, serão trabalhadas, nos módulos, as dificuldades que foram detectadas, buscando ao longo das atividades superá-las. Neles serão abordadas as diversas características e funcionalidades do gênero em questão. O docente precisa levar os estudantes a conhecer seus possíveis interlocutores, as condições de produção do texto e suas finalidades, assim como evidenciar as particularidades do vocabulário, dos aspectos linguísticos e pragmáticos que compõem o gênero. Nos módulos, ainda, serão trabalhadas atividades de análise de textos e produção,o que, consequentemente, levará os alunos a desenvolver uma linguagem comum (linguagem técnica) entre eles. Por fim, os educandos apresentarão os conhecimentos que foram adquiridos ao longo das atividades.

$\mathrm{Na}$ produção final, será colocado em prática tudo aquilo que foi trabalhado ao longo da sequência, seja a partir da reescrita do primeiro texto, observando as mudanças que ocorreram ou na construção de um novo. O professor, nesta etapa, poderá realizar uma avaliação somativa, analisando o desenvolvimento dos alunos, os aspectos que, ainda, precisariam ser recapitulados, como também se a metodologia empregada alcançou todos os objetivos traçados, no que tange ao domínio do gênero trabalhado. 
Como a produção final compreende a reescrita do texto inicial, essa reescrita poderia ser por meio da "retextualização", como propõe Dell'Isola (2007). A autora assim expõe: "Por retextualização entende-se o processo de transformação de uma modalidade textual em outra, ou seja, trata-se de uma refacção e reescrita de um texto para outro, processo que envolve operações que evidenciam o funcionamento social da linguagem"(DELL'ISOLA, 2007, p. 10).

Essa perspectiva de abordagem de escrita/reescrita de gêneros textuaisproposta por Dell'Isola certamente é uma aliada do fazer pedagógico de produção de texto com foco em um gênero específico, mas a partir de outro gênero. Isso proporciona não só a possibilidade de conhecimento e domínio dos gêneros envolvidos no processo tanto na escrita quanto na leitura, como também amplia o universo de "[...] entendimento da grande variedade de textos, os quais veiculam inúmeras e diferentes linguagens construídas por meio dos gêneros textuais" (DELL'ISOLA, 2007, p. 10).

Acreditamos que a proposta de reescrita e de autoavaliaçãopode atuar no desenvolvimento crítico e na autonomia do discente. As experiências antes adquiridas tornam-se, agora, ferramentas para essa atividade avaliativa. A SD tem, pois, por finalidade maior levar os alunos a reconhecer as suas próprias competências acerca de um gênero textual. Em síntese, "O que é visado é o domínio, o mais perfeito possível, do gênero correspondente à prática de linguagem para que, assim, instrumentado, o aluno possa responder às exigências comunicativas com as quais ele é confrontado" (SCHNEUWLY; DOLZ, 2004, p. 79).

\section{Gêneros textuais segundo a abordagem dos PCN e da BNCC}

As leituras que realizamos, acerca da teoria dos gêneros textuais proposta pelo Interacionismo Sociodiscusivo, possibilitaram perceber que os documentos oficiais PCN e BNCC (área de linguagens - ensino fundamental)estão intrinsecamente relacionados e fundamentados na teoria aqui apresentada, tendo em vista que expõem e defendem o trabalho com os gêneros textuais como um conteúdo essencial e de cunho pedagógico, apresentando-se como instrumento significativo no processo de ensino de leitura e de escrita.

Os gêneros podem levar o aluno a desenvolver a criticidade frente à linguagem e à sociedade, contribuindo, assim, para a elaboração de seus próprios conceitos, ou seja, o trabalho com gêneros textuais é um método efetivo que possibilita ao aluno a construção de um olhar crítico diante do senso comum, visto que lhe fornece mecanismos para o pleno exercício da cidadania, de forma autônoma e consciente. Para Bazerman (2011), os gêneros textuais levam o sujeito a compreender o mundo com o qual ele se comunica, bem como atuam no desenvolvimento comunicativo, favorecendo o conhecimento acerca de suas próprias habilidades. Por isso, os PCN e a BNCC apontam a importância de trabalhá-los em sala de aula, a fim de proporcionar ao discente uma autonomia intelectual e, consequentemente, sua interação comunicativa no meio social, o que vai possibilitar, de ricochete, resultados significativos.

A Lei de Diretrizes e Bases da Educação Nacional (LDB, Lei n. ${ }^{\circ}$ 9.394/1996) foi criada com o intuito de fornecer ao professor um suporte para o processo de ensino e aprendizagem, visando a um eficaz desenvolvimento da educação brasileira. Essa Lei, que regulamenta o sistema educacional (público ou privado) brasileiro (da educação básica ao ensino superior), propiciou o surgimento dos Parâmetros Curriculares Nacionais, documento que foi publicado em 1997.

Os PCN formam um conjunto de diretrizes que foi criado com a finalidade de orientar as práticas pedagógicas em sala de aula e reformular o ensino a partir de uma ampla organização da matriz curricular de uma instituição educativa. Esse documento oficial serve como subsídio aos professores para que possam desenvolver suas práticas pedagógicas, sobretudo, fazendo com que os conteúdos escolares sejam trabalhados de forma contextualizada e não somente com a simples transmissão dos conhecimentos, o que é bem característico da escola tradicional. Em vista disso, 
e com a intenção de quebrar esse tabu, contribuindo, então, para uma maior dinamicidade da educação, os PCN,

\begin{abstract}
Por sua natureza aberta, configuram uma proposta flexível, a ser concretizada nas decisões regionais e locais sobre currículos e sobre programas de transformação da realidade educacional empreendidos pelas autoridades governamentais, pelas escolas e pelos professores. Não configuram, portanto, um modelo curricular homogêneo e impositivo, que se sobreporia à competência político-executiva dos Estados e Municípios, à diversidade sociocultural das diferentes regiões do País ou à autonomia de professores e equipes pedagógicas. (BRASIL, 1997, p. 13)
\end{abstract}

Os PCN de Língua Portuguesa (1998), por sua vez, fundamentam-se basicamente na teoria interacionista sociodiscursiva e ressaltam a importância de utilizar os gêneros no processo de ensino de leitura e de escrita, a fim de que o discente, com o auxílio do professor, consiga obter êxito em sua formação socioeducacional. Para os PCN-LP (1998), esse êxito está relacionado ao desenvolvimento do senso crítico no aluno, o que irá contribuir para a sua plena participação na sociedade, uma vez que poderá adaptar suas atividades linguísticas com sucesso, aprimorando-as de acordo com os eventos sociais comunicativos no qual está envolvido. De acordo com os PCN (1998), toda educação que realmente tem um olhar voltado para o pleno exercício da cidadania precisa criar condições para que o aluno seja capaz de desenvolver sua competência discursiva no decorrer de sua formação, tornando-se um cidadão proficiente, participativo e autônomo; e nada melhor do que se utilizar dos gêneros textuais, que são ferramentas imprescindíveis no processo de ensino/aprendizagem.

Assim como a perspectiva apresentada por Schneuwly e Dolz (2004), os PCN (1998) defendem o texto como unidade básica para o processo de ensino/aprendizagem, tendo em vista sua contribuição para um trabalho significativo e contextualizado que verdadeiramente evidencia a competência discursiva. Desta forma, podemos observar nesse documento uma abordagem ensino com os gêneros textuais a partir da proposta do ISD, demonstrando uma "evolução" na concepção de ensino de língua portuguesa, distanciando-se das práticas de ensino tradicionais.

Tal como os PCN, a Base Nacional Comum Curricular (BNCC, 2018) foi criada com o objetivo de nortear as práticas pedagógicas de ensino nas escolas, tornando-se uma ferramenta que busca orientar o processo de elaboração do currículo das instituições de ensino, levando em consideração as particularidades metodológicas, sociais e regionais de cada uma. A BNCC se apropria das competências e habilidades que são essenciais para um melhor desenvolvimento no processo de ensino/aprendizagem, objetivando alcançar uma educação de qualidade.

Apesar de serem documentos criados em épocas diferentes, tanto os PCN quanto a BNCC utilizam-se das mesmas diretrizes legais no processo de ensino/aprendizagem e, também, estão pautados na teoria interacionista sociodiscuriva dos gêneros textuais. A BNCC surgiu com a finalidade de estabelecer melhorias no desenvolvimento educacional, reforçando o uso da diversidade de gêneros textuais por acreditar que podem despertar no aluno o interesse pela leitura e, por conseguinte, fazê-lo desenvolver a escrita. Essas duas práticas sociais são indispensáveis na vida do educando. A BNCC defende, ainda, que desde os anos iniciais a criança deve ter contato com os diferentes gêneros textuais a fim de que reconheça a leitura como fonte de conhecimento.

Por fim, além de contribuir para a formação do discente, a BNCC e os PCN constituemse como importantes aliados para o professor, ao disponibilizar um material de referência para que ele utilize no seu trabalho em sala de aula. Desta forma, o trabalho com gêneros textuais, no processo de leitura e de escrita, poderá levar à plena formação do aluno, tornando-o um cidadão crítico e reflexivo frente à sociedade em que está inserido, fazendo-o capaz de "ler o mundo" de forma independente e crítica como um sujeito consciente de seus direitos e deveres políticosociais, ou seja, torne-se um cidadão pleno. 
Diante do exposto, na próxima seção, discutiremos sobre o gênero textual notícia e proporemos a construção de uma sequência didática e sua aplicação pedagógica a partir desse gênero.

\section{Gênero textual, sequência didática e aplicação pedagógica: a notícia em foco}

Buscamos, aqui, abordar,brevemente,o gênero textual notícia, construindo uma ponte para que, em seguida, possamos apresentar, através de uma SD, um trabalho pedagógico com este gênero.

\subsection{0 gênero textual notícia: o que é?}

A notícia está presente diariamente na vida do cidadão, seja por meio de jornais, revistas, blogs, televisão, rádio ou no relato de um fato em uma conversa com um amigo. Esse gênero de texto esteve sempre presente na sociedade. Antes do surgimento desses instrumentos que, hoje, possibilitam a circulação da notícia, os mensageiros, na antiguidade, já cumpriam esse papel de relatar, geralmente, levando informações às autoridades que estavam em lugares distantes.

A notícia é um gênero textual jornalístico, bem como a reportagem, o editorial e a carta do leitor. No entanto, possui características específicas, determinadas em função de um objetivo comunicativo. Segundo os PCN (1998, p. 21), "Todo texto se organiza dentro de determinado gênero em função das intenções comunicativas, como parte das condições de produção dos discursos, as quais geram usos sociais que os determinam". Desta forma, os gêneros textuais são construídos a partir das necessidades sociocomunicativas do sujeito e cada gênero apresenta especificidades e molda-se conforme a intenção dos seus falantes.

Baltar (2004 apud CAREGNATTO, 2008) define notícia como um gênero genuinamente informativo que tem como propósito relatar um fato cotidiano relevante, no qual o jornalista não se posiciona e nem argumenta, pois o destaque da produção está no fato ocorrido (pelo menos, em princípio!). Por isso deve prevalecera impessoalidade: as informações são relatadas em terceira pessoa sobre fatos ou acontecimentos ocorridos no dia a dia. Os verbos são utilizados no indicativo, expressando que os acontecimentos são verídicos e que os fatos transmitidos são seguros, pois não é suficiente que a notícia seja verdadeira, ela precisa ser transmitida de forma que pareça verdadeira. Com uma linguagem objetiva, o autor procura levar a notícia de forma mais clara possível, deixando de lado expressões que possam vir a transmitir uma subjetividade. Como o público ao qual se destina a notícia é múltiplo e, algumas vezes, não se conhece bem o seu perfil, há um equilíbrio entre a linguagem culta e a coloquial, buscando alcançar o maior número possível de leitores. Portanto, a adequação lexical ao público-alvo esperado da notícia é essencial para que haja sucesso na produção e recepção desse gênero textual.

Contudo, é preciso dizer que isso é bastante questionável na medida em que as visões dos jornais $\mathrm{X}, \mathrm{Y}$ e $\mathrm{Z}$ sobre um determinado fato podem ser bastantes diferentes, dependendo dos interesses político-econômicos envolvidos. Isso é muito comum.Até porque a seleção de fatos sobre uma notícia já é uma postura ideológico-argumentativa direcionada a/para esses interesses.

Posto isso, passemos à análise de uma notícia retirada do portal de internet $\mathrm{R} 7$, buscando apresentar a arquitetura do gênero em questão.

Professor é decapitado em possível ataque terrorista na França ${ }^{5}$

A vítima era um professor de bistória que usou caricaturas que satirizam Maomépara os alunos; o assassino morreu em confronto com a policia

\footnotetext{
${ }^{5}$ https:// noticias.r7.com/internacional/professor-e-decapitado-em-possivel-ataque-terrorista-na-franca-16102020
} 
Um professor de bistória foi decapitado na saída da escola onde ele lecionava, na pequena cidade de ConflansSainte-Honorine, a cerca de $30 \mathrm{~km}$ de Paris, capital da França. O crime, que está sendo investigado como um ataque terrorista, ocorreu na tarde desta sexta-feira (16).

Segundo as primeiras informações, o professor teria mostrado caricaturas da revista Charlie Hebdo que satirizam Maomé em uma aula sobre liberdade de expressão e por isso se tornou alvo do ataque.

Quando os policiais chegaram ao colégio, encontraram o autor do crime ao lado do prédio escolar, com uma faca na mão. Quando pediram que ele colocasse a lâmina no chão, ele se recusou e foi baleado pelos agentes.

O homem, que supostamente estaria com um colete de explosivos, morreu no local. A escola foi evacuada para que o esquadrão anti-bombas pudesse verificar se ele realmente estava com bombas no corpo. Ainda não bá confirmação sobre motivações e sobre a identidade do autor do crime.

O presidente da França, Emmanuel Macron, foi para a cidade para acompanhar o desenrolar do caso.

A estrutura da notícia se inicia pelo título principal(Professor é decapitado em possivel ataque terrorista na França), chamado ainda de "manchete", que tem como objetivo apresentar de forma sucinta e atrativa o tema da notícia. Em seguida, vem o título auxiliar ou "olho da notícia" que tem como propósito acrescentar informações adicionais à ideia do título principal (A vítima era um professor de história que usou caricaturas que satirizam Maomé para os alunos; o assassino morreu em confronto com a polícia).

O lead, geralmente é o primeiro parágrafo da notícia, corresponde ao resumo do conteúdo que estará presente no texto. Ele deve apresentar os fatos de forma que despertem a atenção do leitor para continuar a leitura e trabalhar a capacidade de síntese das informações, buscando responder às seguintes questões: o quê? (Professor foi decapitado); quem? (Professor de História);como? (foi decapitado na saida da escola);onde? (na pequena cidade de Conflans-Sainte-Honorine, a cerca de $30 \mathrm{~km}$ de Paris); quando? (Sexta-feira, dia 16 de Outubro de 2020). O por quê? vem no corpo do texto (o professor teria mostrado caricaturas da revista Charlie Hebdo que satirizam Maomé).

Dessa forma, podemos verificar que o texto aqui apresentado cumpre com essa missão, transmitindo ao público-alvo um fato atual de impacto nacional e internacional ocorrido na França, a saber, um possível atentado terrorista que vitimou um professor de história que teria mostrado, em uma aula sobre liberdade de expressão, caricaturas que satirizam Maomé. Por fim, temos o corpo da notícia que consiste na exposição mais detalhada dos acontecimentos, como podemos verificar no segundo, terceiro, quarto e quinto parágrafos.

Como havíamos mencionado anteriormente, a notícia é conduzida por uma suposta "impessoalidade", fornecendo apenas dados e deixando que o leitor tire suas próprias conclusões. Todavia, Stella (2008 apud CAREGNATTO, 2008, p. 13) defende que a palavra

[...] pode assumir qualquer função ideológica, dependendo da maneira em que aparece num enunciado concreto. Além disso, pode ser entendida como um "signo neutro", não no sentido de que não tenha "carga ideológica", mas no sentido de que, como signo, como conjunto de virtualidades disponíveis na língua, recebe carga significativa a cada momento de seu uso.

Perante o exposto, vale ressaltar a importância da formação de sujeitos críticos que não sejam apenas receptores de informação, mas que tenham um ato responsivo na leitura para que não sejam alvos de fácil manipulação. O estudo desse gênero, segundo essa perspectiva, é essencial para demonstrar que algumas vezes a notícia é tomada como objeto de persuasão e convencimento. Apesar da impessoalidade defendida, sabemos que o sujeito é um ser social, dotado de questões ideológicas e que mesmo buscando expressar-se com total neutralidade, transmite de forma implícita suas ideologias.

Além de ferramenta de comunicação, a notícia também é um veículo formador de opiniões. Assim, se faz necessário observar que por trás dos fatos relatados pode haver uma intervenção política e econômica. É nesse momento em que o docente precisa trabalhar a leitura, no intuito de proporcionar ao aluno uma autonomia e um juízo crítico mediante as informações 
que circulam nos meios de comunicação. Os manuais de redação tendem a enfatizar uma total impessoalidade na produção do gênero notícia. Acerca disso, acreditamos que o autor da notícia deve buscar ao máximo um compromisso ético com a verdade, todavia os educandos devem ter ciência de que é impossível uma imparcialidade total, pois até mesmo as escolhas temáticas e lexicais transmitem nossas ideologias. Isso porque, conforme Volochínov (2013, p. 169), “A orientação social é uma das forças vivas organizadoras que, junto com a situação da enunciação, constituem não só a forma estilística, mas também a estrutura puramente gramatical da enunciação."

Portanto, para que o trabalho com o gênero notícia atue no desenvolvimento da leitura e da escrita de forma crítica, o professor precisa levar o aluno a uma reflexividade, apresentando a composição sociocultural, os objetivos e as intenções comunicativas que atuam por trás do gênero. Enfim, temos por finalidade propor, através de uma SD, atividades que alcancem esses objetivos. Como ilustração da proposta apresentada, elaboraremos uma SD com o gênero notícia.

\subsection{Uma sequência didática com o gênero notícia}

Mediante as discussões apresentadas em torno da SD, buscamos, baseados nessa proposta pedagógica, traçar atividades que levem o discente ao desenvolvimento da leitura e da escrita a partir do domínio do gênero em foco.

Ano: $9^{\circ}(\mathrm{EF})$

\section{SEQUÊNCIA DIDÁTICA}

Tempo estimado: uma unidade.

Objetivos:

- Despertar o interesse do educando pela leitura e pela escrita através do gênero notícia.

- Desenvolver a escrita e a leitura crítica e reflexiva a partir da análise e produção de textos.

- Levar o aluno a apropriar-se do gênero notícia.

- Ampliar as competências discursivas do educando.

Metodologia:

Levar o discente a observar o caráter sociodiscursivo do gênero notícia.

- $\quad$ aulas dialogadas;

- $\quad$ reescrita/retextualização de um texto poético para a notícia;

- $\quad$ análise do gênero notícia a partir dos diversos meios de comunicação em que circula;

Material necessário: produção coletiva e individual de textos.

- $\quad$ notebook; data show; caixa de som; revistas; jornais.

\section{Desenvolvimento (etapas):}

1. Apresentação do gênero notícia, através de exemplos de notícias retiradas de uma revista e deum canal da internet. Logo em seguida, debate em grupo dos temas abordados nos exemplos de notícias e das características iniciais que foram observadas, tanto na produção oral como na escrita.

2. Estudo do contexto histórico-social da formação do gênero em foco, leitura de notícias retiradas de um jornal local, análise linguística e social dos textos e produção individual de uma notícia a partir das temáticas que foram abordadas.

3. Análise de duas notícias, uma publicada em jornal e outra em um site, observando todos os aspectos discursivos, ou seja, quais os possíveis destinatários das notícias? Qual o objetivo dos autores? Quais os temas abordados? Qual o tipo de linguagem predominante? O assunto é interessante e relevante para a sociedade? Qual o contexto de produção?

4. Leitura e retextualização de um texto poético para a notícia. Nessa etapa serão exploradas atividades com operações gramaticais, bem como leitura e a interpretação crítica do texto. No processo de retextualização, os alunos serão norteados a partir das seguintes questões: Qual o público-alvo de ambos os gêneros em questão? A linguagem utilizada no texto poético está 
adequada à notícia? A arquitetura do texto poético está de acordo com as características da notícia, atendendo ao objetivo deste gênero?

5. Reescrita do primeiro texto e produção coletiva de uma notícia, na qual cada grupo ficará com um tema, como política, meio ambiente, esporte e educação, partindo de seu contexto social para a produção. Em seguida as notícias serão encaminhadas para publicação em um jornal local.

\subsection{Uma aplicação pedagógica do gênero notícia}

Nesta subseção, ilustramos como desenvolver a sequência didática proposta, aplicada ao trabalho com o gênero notícia, explorando a leitura e a escrita. Nesse sentido, primeiro, exploramos a leitura com análises dos aspectos linguísticos, gramaticais e formais dos gêneros envolvidos na atividade ${ }^{6}$ : o poema e a notícia. Em seguida, exploramos a escrita fazendo uso do processo de reescrita/retextualização do texto poético para a notícia.

\subsubsection{Leitura e análise: explorando os sentidos}

Antes de chegar à produção do texto, primeiro exploramos a leitura, o que implica o contato com o gênero objeto de ensino em foco. Sendo assim, buscamos trabalhar um texto motivador para "dar o pontapé inicial", como o que segue:

Poema Tirado de uma Notícia de Jornal

João Gostoso era carregador de feira livre e morava no morro da Babilônia num barraco sem número

Uma noite ele chegou no bar Vinte de Novembro

Bebeu

Cantou

Dançou

Depois se atirou na Lagoa Rodrigo de Freitas e morren

afogado.

(In: Libertinagem, de Manuel Bandeira)

Procuramos apresentar, aqui, uma aplicação pedagógica do gênero notícia a partir do poema de Manuel Bandeira, intitulado "Poema tirado de uma notícia de jornal". Nosso objetivo é analisar esse texto poético e propor a sua reescrita/retextualização, transformando-o em uma notícia jornalística. Outrossim, abordaremos, por meio dele, atividades voltadas à gramática reflexiva e à leitura crítica, como propostas a serem seguidas pelos professores. A forma como iremos trabalhar os gêneros textuais, nessa subseção, é, apenas, uma das maneiras de como a proposta teórico-metodológica discutida pode ser direcionada.

Sabemos que o ensino de leitura e de escrita deve partir de procedimentos contextualizados que favoreçam o desenvolvimento de habilidades linguageiras para que, assim, o aluno possa atuar como agente crítico no exercício sociopolítico. Iniciemos, pois, com a leitura e interpretação do poema, buscando um olhar crítico e reflexivo, além de analisar o contexto social de sua produção.

Arrigucci Jr. (1990 apud PEREIRA, 2016), em "A poesia de Manuel Bandeira: humildade, paixão e morte", apresenta uma análise acerca do "Poema tirado de uma notícia de jornal". Para o crítico, o título do poema pressupõe "[...] que a poesia possa ser tirada de algo; no caso, inesperadamente, de uma coisa tão cotidiana, prosaica, heterogênea, fugaz como a matéria jornalística” (ARRIGUCCI JR., 1990apud PEREIRA, 2016, p. 4 [grifo no original]).

Partindo do que aponta o crítico, podemos, então, verificar que influências de tendências artísticas da época, como o dadaísmo, cujo objetivo incluía a incorporação de qualquer objeto às

\footnotetext{
${ }^{6}$ Essa proposta de atividade já foi devidamente aplicada em sala de aula, em turmas de sexto ano, pelo coautor, quando professor do Ensino Fundamental.
} 
obras de arte, podem explicar essa valorização do cotidiano, na obra, pelo autor. Sendo assim, Manuel Bandeira pode ter se inspirado numa notícia jornalística, o que o levou a ressignificar os elementos desse texto não-literário, que passaram da função de informar à função de instigar a reflexão dos leitores, levando-os a um olhar crítico, sobretudo, a respeito do aspecto social do fato narrado.

Manuel Bandeira organiza os elementos do poema no intuito de instigar o leitor a uma reflexão acerca da condição de vida do personagem. Como podemos verificar, João Gostoso é um homem de origem simples, descrito pelo eu lírico como carregador de feira livre, uma subprofissão, que tem como característica principal o trabalho braçal e a baixa remuneração. Além disso, o personagem reside num morro localizado no Rio de Janeiro, ambiente estereotipado como pobre e marginalizado: a favela da Babilônia. Como afirma o autor, o barraco onde João Gostoso morava era sem número, o que aponta para o desconhecimento do local, no qual residia, reforçando sua marginalização. Sabemos que na sociedade atual, o sobrenome indica a origem do sujeito, todavia "Gostoso" em nada parece exercer essa função, pelo contrário, este sobrenome evidencia que a origem do personagem é desconhecida, sugerindo que no meio social ele era visto como um indivíduo de identidade incerta.

Ao relacionar tais informações, o poema leva os leitores a contemplarem um sujeito discriminado pela sociedade, um "favelado", figura que, dificilmente, ocuparia o centro de uma obra de arte. Assim, Bandeira promove a dessacralização da arte, tendência que marca a produção artística de sua época. Por meio desse poema, o autor constrói um retrato representativo dos indivíduos marginalizados que vivem na periferia, onde predominam as subprofissões, como a de João Gostoso.

Podemos verificar, ainda, que os verbos "beber", "cantar" e "dançar" presentes no poema demostram uma ação prazerosa do personagem. Entretanto, o que leva alguém, após momentos de alegria, a cometer suicídio? Consideremos, pois, que este divertimento tenha sido, apenas, uma forma de ocultar tudo que estava se passando em sua vida, como uma "válvula de escape" para seus problemas. Diante da sequência das ações verbais, indagamos se o motivo, pelo qual João Gostoso, naquela noite, atira-se na lagoa, poderia estar relacionado à realidade de seu contexto social e aquela noite de euforia, provavelmente motivada pela bebida, foi escolhida para encerrar um ciclo de miséria. O personagem faz parte de uma classe sem poder aquisitivo e isso, é fato, dificulta sua sobrevivência na sociedade. Partindo dessas especulações, portanto, o professor pode levar o aluno a uma análise acerca das questões sociais e econômicas que nos rodeiam.

Depois desta breve leitura e interpretação, o professor pode trabalhar, também, por meio do poema, as classes de palavras, análises linguísticas entre outros conteúdos, partindo de uma gramática reflexiva. Nesse sentido, podemos analisar, por exemplo, por meio do trecho "Depois se atirou na Lagoa Rodrigo de Freitas e morreu afogado", a função desempenhada pelo pronome "se".

O pronome "se" evidencia que João Gostoso não foi empurrado na lagoa, mas que, na verdade, cometeu suicídio. O "se", aqui, é classificado pela gramática como pronome reflexivo, isto é, ele indica que o próprio sujeito pratica e sofre a ação de atirar. Nessa sentença, o verbo "atirou" requer um complemento, e o "se" está exercendo essa função, ou seja, podemos compreender esse trecho do poema da seguinte forma: "Depois atirou a si mesmo na Lagoa Rodrigo de Freitas e morreu afogado".

O professor pode tomar este pronome para explicar outras funções, além desta já discutida. O "se" pode ser classificado, também, dependendo da sentença, como pronome reflexivo recíproco. Imaginemos que o poema fala a respeito de um casal, João Gostoso e Maria Bonita, e que ambos, ao invés de "atirarem-se" na lagoa, "abraçarem-se". Logo, o eu lírico diria, por exemplo: "Depois se abraçaram na Lagoa Rodrigo de Freitas e voltaram para casa". A princípio, o verbo "abraçar", assim como o verbo "atirar", pede um complemento. O "se", mais 
uma vez, desempenha essa função, mostrando que as personagens em um ato considerado pela gramática como recíproco, praticam e sofrem uma ação mútua, ambos abraçam um ao outro.

Vale ressaltar que a partir do verbo atirar no contexto do poema, o docente, também, pode discutir a transitividade verbal, ressaltando que tal verbo pode mudar de transitividade dependendo do contexto em que está inserido. Mais uma vez, no trecho "Depois se atirou na Lagoa Rodrigo de Freitas e morreu afogado", o "se" torna o verbo "atirar" um verbo pronominal na voz reflexiva, pois a ação é sofrida pelo próprio sujeito, que, diga-se de passagem, é desinencial na oração aí destacada. Nesse caso, o "se" é classificado gramaticalmente como um pronome apassivador, pois leva o verbo "atirar" para a voz passiva sintética.

Posto isso, os discentes podem refletir sobre o uso do "se" para indicar ações movidas contra o próprio sujeito, buscando verbos em que essa partícula seja mais que um pronome apassivador, seja parte integrante do verbo, como em "suicidar-se", "arrepender-se"; e verbos em que o "se" não seja parte integrante, como o verbo "atirar" no trecho analisado, que pode ser definido como pronominal acidental ou eventual, pois pode ser empregado na voz ativa e passiva, como em "atiram-se pedras" e "atirei o pau no gato".

Já acerca das funcionalidades e especificidades dos gêneros poema e notícia, estabelecemos uma breve comparação entre ambos. Em primeiro lugar, o poema é estruturado em verso, já a notícia apresenta-se em prosa. Aquele não apresenta elementos como manchete, título auxiliar e lead que são característicos deste. A notícia tem por objetivo relatar um fato importante que desperte o interesse do público-alvo, suas informações são expressas em uma linguagem simples e objetiva. Já o poema é um texto literário, caracterizado por uma linguagem subjetiva, que permite trazer para realidade as emoções e sentimentos mais profundos do leitor, além de despertar nele reflexões e críticas sociais, levando-o a inúmeras indagações.

\subsubsection{O processo de retextualização: explorando a escrita}

Diante do que foi discutido nas breves análises da subseção anterior, partimos, agora, para a reescrita do poema. A ação de linguagem solicitada é reescrever, ou seja, retextualizar o poema em uma notícia a partir dos elementos contidos no texto poético. Uma possibilidade de reescrita do texto poético em uma notícia é a que segue:

\section{Homem morre afogado \\ Carregador de feira livre comete suicídio após atirar-se na Lagoa Rodrigo de Freitas}

Na noite dessa terça-feira, 21 de janeiro de 2020, por volta das 23bs, João Gostoso, como era conbecido,atirou-se na Lagoa Rodrigo de Freitas e morreu afogado. Segundo o relato de alguns amigos, na noite de sua morte, ele esteve no bar Vinte de Novembro, bêbado, cantou e dançou a noite toda.

João Gostoso era carregador de feira livre eresidia no morro da Babilônia, num barraco sem número. Seu corpo foi encontrado, somente, no outro dia pela Guarda Civil. Esta informa que, logo pela manhã, foi acionada por feirantesque informaram que o colega João Gostoso havia desaparecido. A Policia Civil também esteve naLagoa Rodrigo de Freitas e, verificando as imagens de câmeras próximas ao local, afirmou que o sujeito cometeu suicídio, atirando-se na lagoa.

Por fim, cabe ressaltar que essa proposta de reescrita/retextualização do poema para a notícia trabalha questões como a dinamicidade dos gêneros textuais e sua capacidade de se adequar a diversas situações comunicativas. Para elaborar uma notícia a partir do poema, foi preciso modificara estrutura e a linguagem deste, levando, pois, o aluno a trabalhar suas capacidades linguísticas.

\section{CONSIDERAÇÕES FINAIS}

Considerando que é dever das instituições educativas formar cidadãos críticos, proficientes em sua língua, bem como, proporcionar ao aluno ferramentas com as quais ele possa 
interagir com a sociedade, podemos afirmar que os gêneros textuais possibilitam o alcance desses objetivos, trabalhando o desenvolvimento da leitura e da escrita como prática social e favorecendo, ainda, a interação do sujeito em meio às diversas atividades comunicativas.

Todavia, para que os gêneros possam atuar efetivamente no processo de ensino/aprendizagem é preciso apresentá-los de forma que despertem o interesse do aluno e como ferramentas que estão presentes diariamente em suas vidas. Para isso, a mediação através da SD é essencial, uma vez que possibilita a construção de situações comunicativas reais, adaptando-se ao contexto social do discente e atuando no desenvolvimento das competências discursivas.

A proposta teórica aqui apresentada é um caminho que pode ser trilhado pelos docentes no complexo e significativo ensino de leitura e de escrita, buscando como premissa maior uma renovação nas atividades educativas. Por isso, em acordo com Dolz, Noverraz e Schneuwly (2004), é preciso criar contextos de produção precisos, assim como efetuar atividades ou exercícios múltiplos e variados, porque é isso que permitirá aos alunos apropriarem-se das noções, das técnicas e dos instrumentos necessários ao desenvolvimento de suas capacidades de expressão oral e escrita, em situações de comunicação diversas.

Dessa forma, podemos observar que o trabalho com atividades diversas e inovadoras deve ser objeto e ponte pelo qual o professor deve seguir. Só através de uma inovação pedagógica que vise um ensino pautado no desenvolvimento das habilidades discursivas e no uso da linguagem em diversas situações de comunicação, é que o discente poderá sentir-se atraído pelos instrumentos de ensino e, assim, desenvolver a prática de letramento no seu dia a dia.

\section{REFERÊNCIAS}

BAKHTIN, M. M. Os gêneros do discurso. Organização, tradução, posfácio e notas de Paulo Bezerra; notas da edição russa de Serguei Botcharov. São Paulo: Editora 34, 2016.

BANDEIRA, M. Poema tirado de uma notícia de jornal. Disponível em: http://valiteratura.blogspot.com/2012/03/poema-tirado-de-uma-noticia-de-jornal.html. Acesso em: 20 mar. 2020

BAZERMAN, C. Gêneros textuais, tipificação e interação. DIONÍSIO, Ângela Paiva; HOFFNAGEL, Judith Chambliss (Orgs.). Trad. e adap. Judith Chambliss Hoffnagel. 4. ed. São Paulo: Cortez, 2011.

BRASIL. Base Nacional Comum Curricular: ensino fundamental. Brasília: MEC/Secretaria de Educação Básica, 2018.

BRASIL. LDB: Lei de Diretrizes e Bases da Educação Nacional. 3. ed. Brasília: Senado Federal, Coordenação de Edições Técnicas, 2019.

BRASIL. Parâmetros Curriculares Nacionais. Introdução aos parâmetros curriculares nacionais. Brasília: MEC/SEF, 1997.

BRASIL. Parâmetros Curriculares Nacionais. Língua portuguesa: terceiro e quarto ciclos. Brasília: MEC/SEF, 1998.

BRONCKART, J-P. Atividade de linguagem, textos e discursos. Por um interacionismosociodiscursivo. Trad. Anna Rachel Machado e Péricles Cunha. São Paulo: EDUC, 1999. 
CAREGNATTO, M. F. P. Modelo didático do gênero textual notícia impressa. Disponível em: < http://www.diaadiaeducacao.pr.gov.br/portals/pde/arquivos/2002-6.pdf $>$. Acesso em: 18 de mar. 2020.

CRISTOVÃO, V. L. L.; NASCIMENTO, E. L. Gêneros textuais e ensino: contribuições do interacionismosociodiscursivo. In: KARWOSKI, A. M.; GAYDECZKA, B.; BRITO, K. S. (Orgs.). Gêneros textuais: reflexões e ensino. 4. ed. São Paulo: Parábola Editorial, 2011. p. 3352.

DELL'ISOLA, R. L. P. Retextualização de gêneros escritos. Rio de Janeiro: Lucerna, 2007.

DOLZ, J.; NOVERRAZ, M.; SCHNEUWLY, B.Seqüências didáticas para o oral e a escrita: apresentação de um procedimento. In: SCHNEUWLY, B.; DOLZ, J. (et colab.). Gêneros orais e escritos na escola. Trad. e org. Roxane Rojo;Glaís Salles Cordeiro. Campinas: Mercado de Letras, 2004. p. 95-128.

FRANÇA, J. M.A didatização de um gênero do argumentar: a carta do leitor. In: FRANÇA, J. M. (org.). Estudos linguísticos e ensino de língua: abordagens. São Cristóvão: Editora da UFS, 2012. p. 151-168.

MARCUSCHI, L. A. Produção textual, análise de gêneros e compreensão. São Paulo: Parábola Editorial, 2008.

PEREIRA, C. M. "A dor da gente não sai no jornal”: poesia, canção e política. Recorte, Minas Gerais, v. 13, n. 1, p. 1-14, jan/jun 2016.

SCHNEUWLY, B.; DOLZ, J. Os gêneros escolares: das práticas de linguagem aos objetos de ensino. In: SCHNEUWLY, B.; DOLZ, J. (et colab.).Gêneros orais e escritos na escola. Trad. e org. RoxaneRojo;Glaís Salles Cordeiro. Campinas: Mercado de Letras, 2004. p. 71-91.

VOLOCHÍNOV, V. N. A construção da enunciação e outros ensaios. Trad. João WanderleyGeraldi. São Carlos: Pedro \& João Editores, 2013. 